(C)2007 IEEE. Personal use of this material is permitted. However, permission to reprint/republish this material for advertising or promotional purposes or for creating new collective works for resale or redistribution to servers or lists, or to reuse any copyrighted component of this work in other works must be obtained from the IEEE 


\title{
Multi-site Project Organisation Knowledge Sharing Ontology
}

\author{
Hai Dong, Farookh Khadeer Hussain and Elizabeth Chang \\ Digital Ecosystems and Business Intelligence Institute \\ Curtin University of Technology \\ Perth, Australia
}

\begin{abstract}
The implementation of ontology starts to step into the field of project organizations. With the appearance of project outsourcing, the location of project workplace becomes increasingly multiple, which challenges the administration of senior management to projects. In this paper, we analyze the daily knowledge sharing activities, including the organizational structure, the procedure of project planning and the scenarios of project distribution, by a case study in City of Melville Council a typical multi-site project organization, to discover the issues in these activities. By means of extending the theory of CCCI Metrics into the field of project management, we design the multi-site project track and trace ontology, in order to promote the knowledge sharing activities between senior management and project groups.
\end{abstract}

Keywords- knowledge sharing, ontology, project organisation

\section{INTRODUCTION}

One characteristic feature of multi-site project organizations is that people in the organizations are geographically dispersed [3]. With the increase of project outsourcing, project groups and its members are probably located in different areas, from different cultural background and even speak different languages [2]. These issues challenge the administration of senior management on projects in project organizations. However, until now there is not an existing methodology for tracking project procedures in project organizations.

In this paper, by means of a case study, we will analyze the issues existing in the current knowledge sharing activities in project organizations. Then the theory of CCCI Metrics will be introduced to solve the issues. Based on the theory, an ontology-based multi-site project track and trace methodology will be proposed to promote the knowledge sharing activities in project organizations.

\section{IsSUeS IN KnOwledge Sharing Activities IN MUlti- SITE PROJECT ORGANIZATIONS}

\section{A. Typical Knowledge Sharing Activities in Multi-site Project Organizations}

To deeply study knowledge sharing activities in project organizations, we choose a typical project organization as the object of the research, which is City of Melville Council (www.melville.wa.gov.au).

In the typical project organization, the organizational structure is as shown in Figure 1.CEO is responsible for the whole organization which consists of several departments. Directors are responsible for departments which consist of several divisions. Managers are responsible for divisions which consist of several personnel.

As a project organization, to plan and implement projects is the primary task of the organization. In the City of Melville Council, the process of project planning can be drawn as:

Step 1: Normally projects are drafted by one or more than one directors of departments.

Step 2: Then the directors hand in the project drafts to the Council Board which consists of CEO and consultants.

Step 3: The Council Board will evaluate the project drafts.

Step 4: If the project drafts are agreed, the projects will be distributed by CEO to the directors who draft the projects.

About the project distribution, normally there are three scenarios which are:

Scenario 1: CEO assigns one project to one of departments; the director of the department in turn is responsible for a part of the project. The director in turn divides the project into several tasks for handling by one or more managers. Each manager and related personnel act in the actual implementation of the tasks.

Scenario 2: CEO assigns several projects to one department; the director of the department is responsible for the projects. The director assigns at least one project to each manager. Therefore, each manager is responsible for managing the implementation of the projects that have been assigned to him/her.

Scenario 3: CEO assigns one project to more than one department, and then the directors of the departments are responsible for the implementation of the project.

\section{B. Issues in the Knowledge Sharing Activities}

The issues existing in knowledge sharing activities in City of Melville are as below: 
- There is not existing methodologies to track and trace projects.

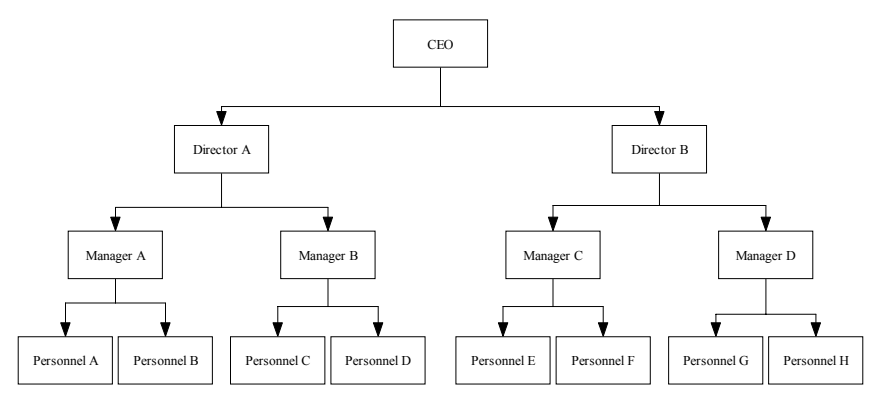

Figure 1. Example of Organizational Structure

- $\quad$ CEO and Council Board do not know about the status of projects currently being processed in organizations.

- Directors cannot duly administrate the responsible projects owing to the lack of the necessary information about the projects.

- Managers cannot realize the real status of projects being implemented.

- If many people implement one project at the same time, they could not clearly distinguish their responsibilities.

- There is no criterion for assessing the completion of projects.

\section{ONTOLOGY}

In this section, we discuss a formal definition of ontology from the literature. There are many definitions of ontology from various aspects. From philosophical aspect, ontology is "a discipline of philosophy, which is meta-physics dates back to Aristotle". The other definitions of ontology are as follows: "the science of what is", "the study of what is possible" or "the study of the nature and structure of possibilia" [5]. From technological aspect, ontology is "an explicit machine-readable specification of a shared conceptualization" [4]. Ontology is "a specific artifact designed with the purpose of expressing the intended meaning of a shared vocabulary", "a shared vocabulary plus a specification of its intended meaning" or "a specification of a conceptualization" [5]. Various notation systems are used to represent ontology. The benefit of ontology is that by means of organizing knowledge in specific domains, ontology may be utilized to promote knowledge sharing within organizations or inter-organizations [4].

\section{Utilizing CCCI Metrics for Project Management}

CCCI metrics originates from the works of Chang et al [3], which is a quantitative methodology to assess trustworthiness of service providers. The essence of CCCI metrics theory is to measure the trustworthiness value of the service providers by means of designing various criteria for the providers and quantitatively evaluating the correlation, the clarity and the importance of each criterion. In this paper we extend the CCCI Metrics and apply it to the field of project management to enable ontology based track and trace.

CCCI metrics for project management is utilized to measure the completion status of a project. A project is viewed as being composed of many criteria. Each status or the completion status of each criterion is individually tracked in order to determine the status of the project. In other words, once all criteria have been completed, the project in turn is regarded as complete.

CCCI Metrics for project management comprise four metrics as shown below:

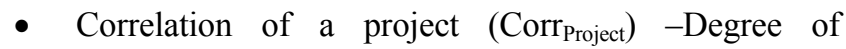
correlation between the actual status of the project (ActualCompetion Project $_{\text {) and the mutually agreed status }}$ of the project or the desired status of the project (MutuallyAgreedCompletion Project). $_{\text {. }}$.

$$
\operatorname{Corr}_{\text {Project }}=\frac{\text { ActualCompetion }_{\text {Project }}}{\text { MutuallyAgreedCompletion }} \text { Project }_{\text {Pred }}
$$

- Correlation of a criterion in the project $\left(\mathrm{Corr}_{\text {Criterion }}\right)$ A metric qualifies the extent of criterion completion in a project. The levels of $\mathrm{Corr}_{\text {Criterion }}$ are shown below:

$$
\begin{aligned}
& 0 \text { - None/ Partially Completed } \\
& 1 \text { - Fully Competed }
\end{aligned}
$$

- Clarity of a criterion $\left(\right.$ Clear $\left._{\text {Criterion }}\right)$ - A metric qualifies the extent whether a criterion is mutually agreed between the person who is evaluating the status of the project and the person who is carrying out the project. The levels of Clear $_{\text {Criterion }}$ are shown below

0 - This criterion is not mutually agreed between the two parties (the person who is evaluating the status of the project and the person who is carrying out the project).

1 - This criterion is mutually agreed between the two parties.

- Importance of a criterion $\left(\operatorname{Imp}_{\text {Criterion }}\right)$ - A Metric expresses the importance of a criterion. The levels of Imp $_{\text {Criterion }}$ are as follows:

$$
\begin{aligned}
& 0 \text { - Not important } \\
& 1 \text { - Important } \\
& 2 \text { - Very important }
\end{aligned}
$$

In terms of the metrics defined and listed above, equation (1) takes the form listed below as equation (2). 
Project Completion Status $=$

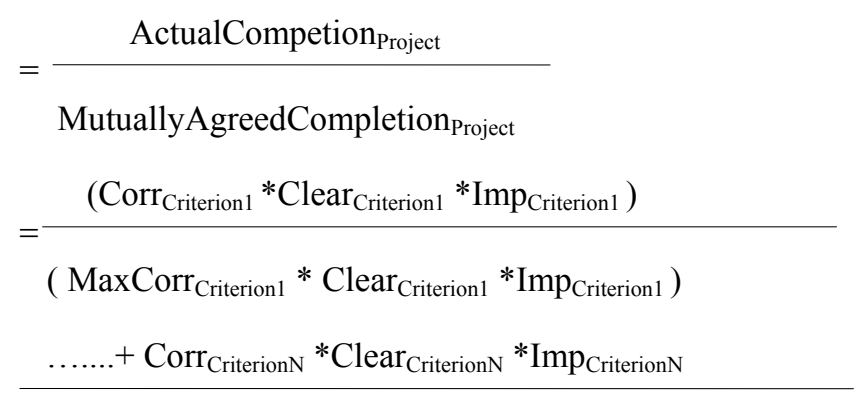

$\ldots+\left(\operatorname{Max} \operatorname{Corr}_{\text {CriterionN }} * \operatorname{Clear}_{\text {CriterionN }} * \operatorname{Imp}_{\text {CriterionN }}\right)$

TABLE I. ONTOLOGY NOTATION SYSTEM

\begin{tabular}{|l|l|}
\hline Ontology Notation & \multicolumn{1}{|c|}{ Semantics of the Notation } \\
\hline & $\begin{array}{l}\text { Double-field Box represents the } \\
\text { Ontological Concepts. }\end{array}$ \\
\hline- relation $-\mathbf{L}$ & $\begin{array}{l}\text { A dotted line represents Ontology } \\
\text { Concept Association Relation which } \\
\text { represents a Concept is closely related to } \\
\text { another concept. The relationship name } \\
\text { can be noted above the dotted line. }\end{array}$ \\
\hline$\longrightarrow$ & $\begin{array}{l}\text { Open-arrow line represents Composition } \\
\text { and Aggregation or Part-of relationship } \\
\text { between Upper Ontology Concept and } \\
\text { Lower Ontology Concept. }\end{array}$ \\
\hline
\end{tabular}

The scope of project completion status includes:

0 - Ignorance

1 - Completely unfinished

2 - Unfinished

3 - Minimally Finished

4 - Partially Finished

5 - Finished

6 - Completely finished

\section{NOTATION SYSTEM FOR ONTOLOGY REPRESENTATION}

The notation system utilized in the ontology representation is based on Chang et al's work, which consists of three basic notations as Table 1.

\section{Multi-Site Project Track and Trace Ontology}

Based on the theory of CCCI Metrics and the ontology notation system, in this section we propose the multi-site project track and trace ontology, which consists of the hierarchy of project organization domain concepts and the ontology of employee and its sub-composition, project ontology and criterion ontology.

\section{A. Hierarchy of Project Organization Domain Concepts}

In a project organization domain, the project organization concept can be seen as a combination of an 'Employee' concept and a 'Project' concept. The 'Employee' concept can refer to:

- 'CEO' who is responsible for managing all projects in Project Organization.

- 'Director' who is responsible for managing the projects which belong to his/her department in the Project Organization.

- 'Manager' who is responsible for managing the projects which belong to his/her division in each department.

- 'Personnel' who are responsible for the implementation of arranged projects.

The graphical view of the hierarchy of Project Organization Domain Concepts is shown in Figure 2 through the use of the ontology notation.

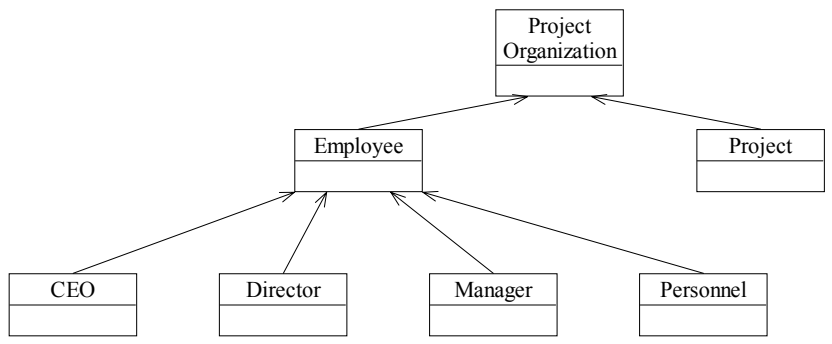

Figure 2. Project Organization Domain Concepts Hierarchy

\section{B. The Ontology of Employee and Its Sub-compositions}

In a project organization, the 'Employee' Ontology is defined as the conceptualization of the 'Employee' who has an Employee Position in the organization and is identified by an Employee Name as well as has Responsibilities which include some Projects (Figure 3)

We present the Employee Ontology as the combination of the ontology name and a tuple where the elements of the tuple can be complex elements as defined below:

Employee [Employee Position, Employee Name and Responsibilities] where:

- 'Employee Position' is a unique identification of Employee in a project organization.

- 'Employee Name' is a unique identification of Employee Position in a project organization.

- 'Responsibilities' is an aggregation of Projects which Employees should take part in. Different Employee Positions are in correspondence with different Responsibilities.

The four sub-compositions of the Employee Ontology CEO Ontology, Director Ontology, Manager Ontology and Personnel Ontology inherit all the relations from Employee Ontology and the only difference is the scopes of the inherited concepts' properties. 


\section{The Relationships between Employees}

In a project organization, a well-conditioned management structure is beneficial to the process of task distribution and progress evaluation. A typical management structure looks as shown in Figure 4.

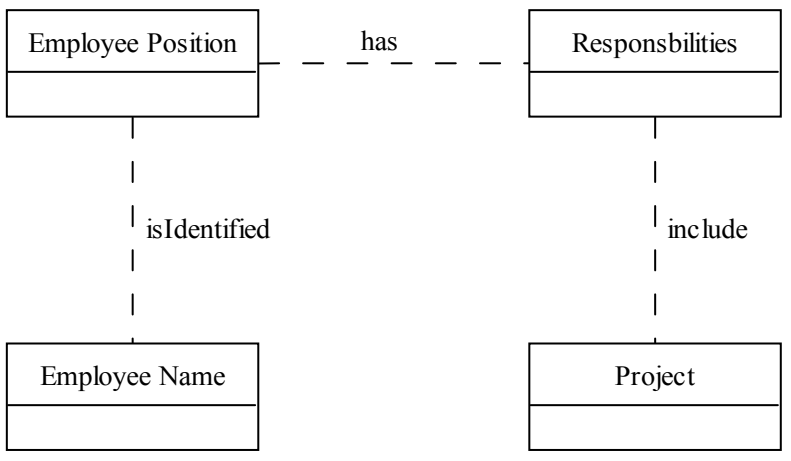

Figure 3. Employee Ontology

\begin{tabular}{|l|l|l|}
\hline CEO & manage & Director \\
\hline & & \\
& & \\
\end{tabular}

Figure 4. Employee Relationships

In project organizations, the CEO manages all directors in the project organization. Then each director supervises at least one given manager and every manager manages at least one given personnel. On the other hand, except for CEO who is not managed by anyone, each member in the project organization has been administrated by the only one.

Owing to the differences of management scopes to different level of Employee, the associations are distinct, which are:

- CEO's management scope is limited in all directors in the Project Organization domain.

- Directors' management scope is the given managers in their departments.

- Managers' management scope is the given Personnel in their divisions.

\section{Project Ontology}

In a project organization, the Project Ontology is defined as the conceptualization of the concept of Project that is identified by Project Code, is shown Date Started, is responsible to Employee and is evaluated by Project Status. (Figure 5)

We represent the Project Ontology as the combination of the ontology name and a tuple where the elements of the tuple can be complex elements as defined below:

Project [Project Name, Project Code, Date Started, Responsible People, Project Status and CCCI Metrics] where:

- 'Project Name' usually refers to a Project itself. In project organization environments, a Project Name is seen as a unique identification for Project.
- 'Project Code' is the mixture of numerical symbols and alphabetic symbols, which also can be seen as the unique identification for Project. The use of Project Code mainly focuses on the storage of Projects' records in databases, which is beneficial to the pick-up and the storage of Projects' documentations.

- 'Date Started' refers to the date when a Project begins to implement. In project management, Date Started can be utilized as a means to measure the length of a Project period which can be evaluated as an important quality aspect and a Criterion of Project.

- 'Responsible People' is an aggregation of Employees who are relevant to a Project.

- 'Project Status' can be substituted as the concept of Project Status Value. Based on the theory of CCCI Metrics, the scope of Project Status Value is from 0 to 6 , which means the different level of Project Status.

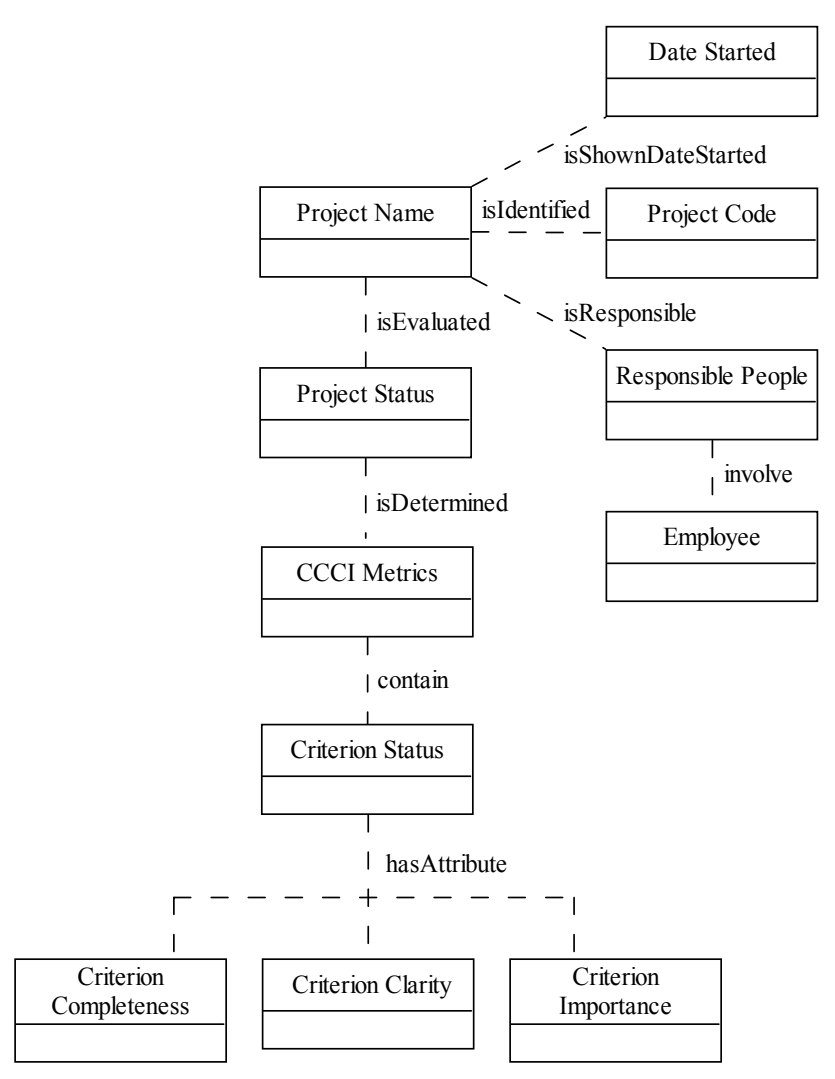

Figure 5. Project Ontology

\section{E. Criterion Ontology}

In project organization environments, the Criterion Ontology is defined as the conceptualization of the concept of Criterion that is identified by Criterion No., Date Logged, and responsible Employee. The attribute Criterion Status has the attributes of Criterion Completeness, Criterion Clarity and Criterion Importance. (Figure 6) 
We represent the Criterion Ontology as the combination of the ontology name and a tuple where the elements of the tuple can be complex elements as defined below:

Criterion [Criterion Name, Criterion No., Date Logged, Responsible Persons, Criterion Status, Criterion Completeness, Criterion Clarity and Criterion Importance] where:

- 'Criterion Name' usually refers to a Criterion itself. In project organization environments, a Criterion Name is seen as a unique identification for Criterion.

- 'Criterion No.' is the mixture of numerical symbols and alphabetic symbols, which also can be seen as the unique identification for Criterion. The use of Criterion No. mainly focuses on the storage of Criteria' records in databases, which is beneficial to the pick-up and the storage of Criteria' documentations.

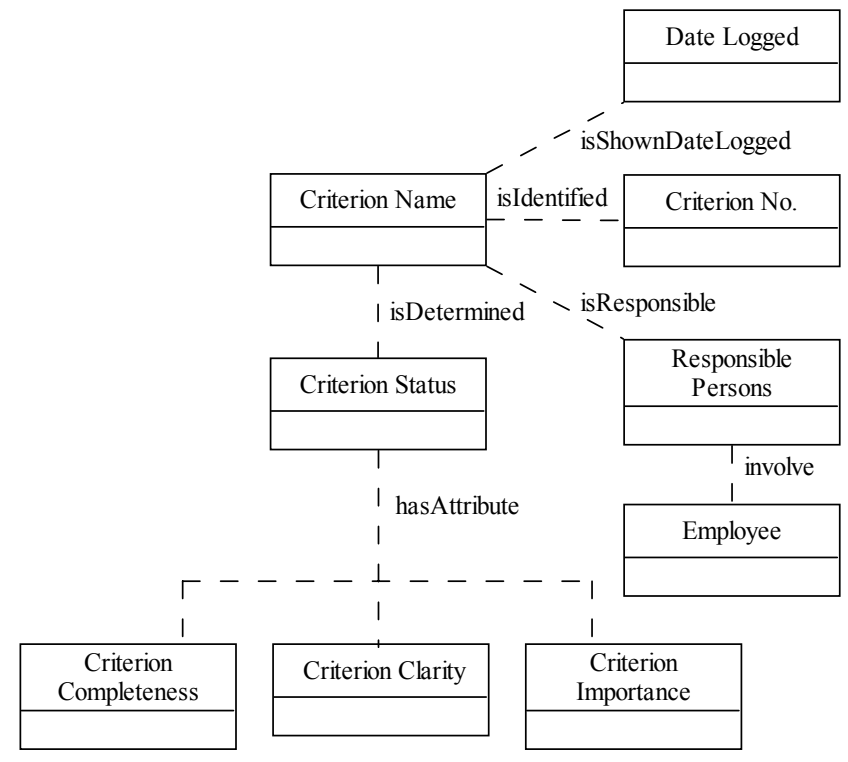

Figure 6. Criterion Ontology

- 'Date logged' refers to the date when a criterion has been mutually agreed between an evaluating person and an evaluated person.

- 'Responsible Persons' is an aggregation of Employees who are relevant to a Criterion.

- 'Criterion Status' is a sub-tuple of the Criterion tuple, which uses quantitative means to determine the extent to which a criterion has been completed or delivered up on the mutually agreed Criterion. It consists of three elements - Criterion Completeness, Criterion Clarity and Criterion Importance.

- 'Criterion Completeness' is an element of Criterion Status, which qualifies the extent of task completion according to its corresponding Criterion.

- 'Criterion Clarity' is an element of Criterion Status, which qualifies the extent whether a Criteria is mutually agreed between an evaluating person and an evaluated person or not in a Project. Its scope is as below:

- 'Criterion Importance' is an element of Criterion Status, which expresses the importance of a Criterion in a Project.

\section{F. The Relationship between Project and Criterion}

As explained previously, a Project can be divided into several Criteria which are in correspondence with tasks or quality aspects of the Project (Fig. 7).

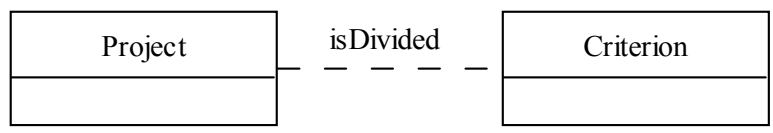

Figure 7. the Relationship between Project and Criterion

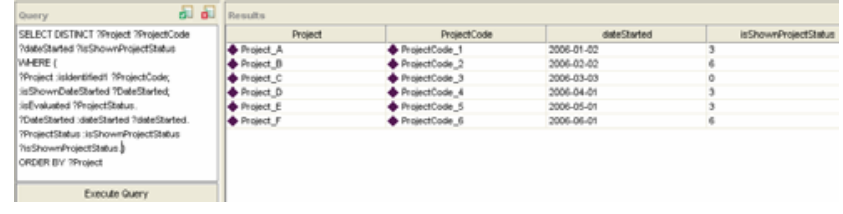

Figure 8. Example of SPARQL Query Result

\section{VAlidation OF PROTOTYPe}

The whole validation process involves two procedures: firstly realizing the multi-site project track and trace ontology by means of Protégé-OWL; secondly validating the ontology by means of SPARQL Query Language for RDF. In terms of query results made by SPARQL, most of the proposed ontologies functions were validated (Fig. 8). Thus, it is believed that the ontology is mostly realized.

\section{CONCLUSION AND FUTURE WORKS}

In the paper, by analyzing the organizational structure, the procedure of project planning and the module of project distribution scenarios in multi-site project organizations, we observe the problematic situation of knowledge sharing activities in the organizations. To solve the issues, we extend the theory of CCCI Metrics in the field of multi-site project management. Finally we borrow the ontology notation system from Chang, Dillon and Hussain [3]'s works to create the multi-site project track and trace ontology. The benefits of this project are concluded as below:

- It realizes the function of tracking and tracing the multi-site project completion status from the perspective of project management, which is to promote knowledge sharing between senior management and actual executors.

- It can be utilized to distinctly define the tasks of each member in projects, and thus avoiding the confusion of members' understanding to own responsibilities.

- It can be utilized to distinctly define completion criteria for each task, the importance and the clarity of each criterion, which is efficient to assist members fully understand their responsibilities. 
- It adopts quantitative methodology to measure the multi-site project completion status, which is effortlessly understood by organizational management.

The limitations of the project are concluded as below:

- The ontology is not tested in practice, and thus we cannot validate its actual contribution to knowledge sharing activities in project organizations.

- On account of the limitation of the time, we have not designed the API to guide users to use and test this system, which could be proposed in the future.

- The scope of current project is only limited in the multi-site project competition status track and trace, which could be expanded in other fields in project organizations, such as the informal information exchange between members, the risk management, the cost management, the quality management and the stage management.

Therefore, in the future works, we will design the user interfaces by Java Language and implement the ontology-based system in client/server networks or peer-to-peer networks in project organizations and we will survey users' satisfaction status to evaluate the system. In addition, we will attempt to expand our research scope to other knowledge sharing activities in multi-site project organizations.

\section{REFERENCES}

[1] E. Chang, T. S. Dillon, and F. Hussain, Trust and Reputation for Service Oriented Environments-Technologies for Building Business Intelligence and Consumer Confidence. IN: John Wiley \& Sons, 2006.

[2] J. J. J. Kasvi, M. Vartiainen, and M. Hailikari, "Managing knowledge and knowledge competences in projects and project organizations," International Journal of Project Management, vol. 21, no. 8, pp. 571582, January 2003.

[3] I. Ruuska, and M. Vartiainen, "Characteristics of knowledge sharing communities in project organizations," International Journal of Project Management, vol. 23, no. 5, pp. 374-379, July 2005.

[4] A. Gómez-Pérez and O. Corcho, "Ontology specification languages for the semantic web," IEEE Intelligent Systems. Washington DC, vol. 17, no. 1, pp. 54-60, February 2002.

[5] N. Guarino, Ontology-Driven Conceptual Modelling, Trento-Roma: Institute for Cognitive Science and Technologies, 2003. 